\title{
How to Look at Pictures
}

\section{Abraham Tamir*}

Ben Gurion University of the Negev, Beer Sheva, Israel

*Corresponding Author: Abraham Tamir, Ben Gurion University of the Negev, Beer Sheva, Israel, Tel:+972 8-646-1600; E-mail: atamir4@012.net.il

Received Date: Jul 25, 2015, Accepted Date: Aug 18, 2015, Published Date: Aug 24, 2015

Copyright: (C) 2015 Tamir A. This is an open-access article distributed under the terms of the Creative Commons Attribution License, which permits unrestricted use, distribution, and reproduction in any medium, provided the original author and source are credited.

\begin{abstract}
This article is about Mona Lisa's gaze where it is accepted for about 500 years that she is looking at her viewers from all directions she is viewed from. However, a thorough experimental study about her view has never been done. As a researcher, the author has decided to check this phenomenon experimentally. 500 people were asked to look at her picture from right, front and left sides. The results were surprising and negate the well-known myth that Mona Lisa looks at the observer from all directions viewed. Only 65\% confirmed that Mona Lisa gave back a look to them. In addition 93\% confirmed that Mona Lisa was looking at them while observing at her from the right, $72 \%$ from the front and $78 \%$ from the left. Following this result brought the author to formulate the following principle: "if you look at any detail in a picture and this detail turns to you, it will turn from each direction you view it: from right, from front, from left, from above and from below. However, if from your looking direction the element does not turn to you, it will never turn to you". Thus, don't view a picture only from the front. Move from right to left and the opposite and you will start to feel that the elements that turned to you from a certain direction will start to "move" in your brain to every direction from which you view them.
\end{abstract}

Keywords Pictures; Mona lisa; Gaze; Florence

\section{Introduction}

Leonardo da Vinci (1459-1519), consummate genius, artist, sculptor, architect, urban planner, inventor, scientist, writer and musician was probably the first to utilize the close interrelationship between Art \& Science. In his Mona Lisa artwork the perception phenomenon of her gaze elaborated in the following is related to psychological sciences. Her enigmatic expression, which seems both alluring and aloof, has given the portrait a universal fame although no one is sure who exactly the lady in the picture is. Here are a few speculations.

According to Vasari, biographer of da Vinci, the subject is a young Florentine woman, Monna (or Mona) Lisa, who in 1495 married the well-known figure Francesco Del Giaconda and thus came to be known as "La Gioconda". According to another speculation, Leonardo recorded in his notebooks the records of model sittings; but nowhere can be found any records of the Mona Lisa model sitting. Why is that? Who posed for him? Schwartz Lillian [1] suggests that Leonardo painted himself, and she supports her contention in the following way. She split the faces of the Mona Lisa and Leonardo's self-portrait down the middle, adjusting the sizes and juxtaposing them so that one side of Mona Lisa's face matches Leonardo's.

This is demonstrated in Figure 1. The two halves form an arresting portrait of a remarkable split personality - the union of a beautiful woman and a bearded man. Another "theory" is the following one. In the book by Solo [2] we are informed that psychoanalytical critics have suggested that Leonardo may have experienced an "Oedipus anxiety" caused by an unresolved sexual fantasy involving his mother, which was manifested in his portrait of a woman.
Here, again, the proof is Lillian's "metamorphosis" of Leo to Mona, from a forbidding Leonardo transformation into a smiling Mona Lisa when age lines and beard are subtracted and the corners of his lips are turned up. And finally, in her intriguing historical novel, Rina de' Firenze [3] claims that the source of inspiration for Leonardo was none other than Caterina, his mother who was a girl of noble blood, whose original name was "Lisa".

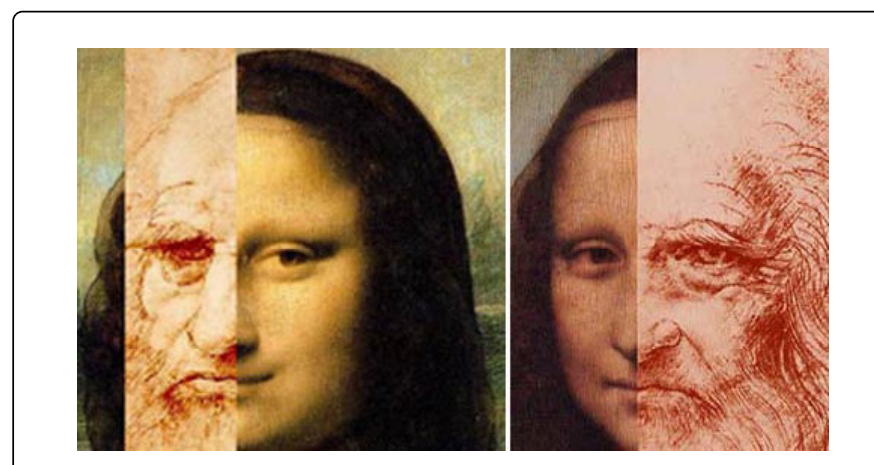

Figure 1: Facial combinations of Mona Lisa and Leonardo da Vinci.

She had an illegitimate child born in 1452 to a well-to-do notary, Piero da Vinci, a child that became the greatest artist, sculptor, architect, and engineer of the Renaissance. His mother adds that when Leonardo entered Verrocchio's studio in Florence, he started drawing her face time and time again, promising her to turn it into the most famous, mysterious painting in the world, which so happened.

Speaking so much about Mona Lisa undoubtedly rises the question what her character might have been. Such an analysis has been made by Lailan Young [4] by applying "face reading" resulting the following character: liar, stubborn, gifted abstract thinker with an IQ above average, greedy, unreliable "friend", would punish her enemy by any 
Page 2 of 3

means, a sneak and finally, needing at least nine hours' sleep each night.

\section{The Gaze of Mona Lisa}

People looking at Mona Lisa, the famous artwork of Leonardo Da Vinci, believe that she looks at them from every direction they look at her. However in a survey the author has conducted, that has never been done before, 500 people were asked to look at her from right, front and left sides.

The results were surprising and negate the well-known myth that Mona Lisa looks at the observer from all directions viewed. Only 65\% confirmed that Mona Lisa gave back a look to them. In addition $93 \%$ confirmed that Mona Lisa was looking at them while observing at her from the right, $72 \%$ from the front and $78 \%$ from the left. What they see from all directions is demonstrated at the top of Figure 2.



Figure 2: The results of looking at the central pictures from left and right.

An additional study of the above results leads to the conclusion that each portrait in a two-dimensional picture will observe at you from each direction, and this is if you indeed felt that the portrait was looking at you from a certain direction.

And indeed also Einstein, as observed from the pictures photographed from all directions - center, left and front - is always looking at the observer.

\section{Mona Lisa Gaze Principle}

A thorough analysis of the subject brought the author to extend and formulate a principle that is named "Mona Lisa's gaze principle" which fits each element in a picture - portrait, wall in a construction, details in a landscape and the like. According to this principle: "If you look at any detail in a picture and this detail turns to you, it will turn to you from each direction you view it: from right, from front, from left, from above and from below. However, if from your looking direction the element does not turn to you, it will never turn to you." The explanation of this phenomenon is as follows. If you look at a three dimensional element then from each direction you see something different. For example if you look a man's face then from the sides you see the profile. However when you look from the front you see the front face. On the other hand when you look at a two dimensional picture, nothing changes when you look from the two sides and the front. Thus if an element in a picture turns to you from a certain direction then it will turn to you from all directions viewed. However, if it does not turn to you from a certain direction it will never turn to you.

An interesting experience of the author is the following. A very famous Israeli photographer presented in Tel Aviv Museum an exhibition. One of his photos was of foreign workers that were turning to the observer. To the surprise of the author the photographer visited his exhibition. The author asked him to stand on the right side and to look at the workers and indeed the photographer confirmed that the workers turned to him. Then the author asked the photographer to look at his photo from the left and the photographer was shocked to reveal that the workers turned to him again as well as when he was standing at the front.

Hence, it is suggested to an observer of a picture the following: move parallel to the picture from right to left and the opposite, and to your surprise you will start to feel that the elements that turned to you from a certain direction will start to "move" in your brain to every direction from which you view them. The artwork of the Holland's artist Meindert Hobbema in Figure 2 indeed testifies that the lane and the woods avenue turn to the observer from each direction. However, The Gate Mercy in the painting of the artist Nofer Keydar never turns to the observer. Twenty-five people who were asked to observe 16 details in the 9 paintings from three directions in which also that at the bottom confirmed the principle in $90 \%$ of the details and the directions of observation. And finally it should be noted that we don't talk here about a scientific principle that exists in all cases, but in a generalization that depends on the perception process that is different from one to the other.

\section{Summary}

This article concludes for the first time into a principle that guides people how to look at pictures a well-known phenomenon. The phenomenon is that when you look at an element in a twodimensional picture, it might turn to you from all directions you view it. This phenomenon is summarized by the following principle: "if you look at any detail in a picture and this detail turns to you, it will turn from each direction you view it: from right, from front, from left, from above and from below. However, if from your looking direction the element does not turn to you, it will never turn to you". More over don't view a picture only from the front. Move from right to left and the opposite and you will start to feel that the elements that turned to 
you from a certain direction will start to "move" in your brain to every direction from which you view them.

\section{References}

1. Schwartz L (1995) The Art Historian's Computer. Scientific American 80-85.
2. Solo RL (1994) Cognition and the Visual Art. The MIT Press, Cambridge, Massachusetts, London, England.

3. De' Firenze R (1996) Mystery of the Mona Lisa. Hastings House Pub.

4. Young L (1993) The Naked Face. St Martin's Press, New York. 